\title{
41. COMPARISON OF SONOBUOY AND SONIC PROBE MEASUREMENTS WITH DRILLING RESULTS
}

\author{
R. Houtz, Lamont-Doherty Geological Observatory of Columbia University, Palisades, New York'
}

\begin{abstract}
Regional velocity functions based on sonobuoy solutions were used to predict four layer thicknesses at three Leg 29 drill sites with an average error of $7 \%$. A computer program (based on an improved $R s-R$, technique) to determine velocity gradients from individual sonobuoy records was applied successfully to data from the New Zealand Plateau and central Tasmanian Sea. Direct comparisons with sonobuoy solutions at or very near drill sites indicated no significant difference between observed and computed data.

Predicted velocity functions and observed mean velocities (based on well-identified reflectors) were compared with Leg 29 sonic probe data. It was observed that the coring process had very little effect on the sonic velocity of sediments taken from below an overburden of about 300 meters thickness, but that sonic velocities measured in sediments with less overburden were much too low. The largest discrepancies occurred in material taken from zones with 200 meters of overburden, where the measured values averaged $180 \mathrm{~m} / \mathrm{sec}$ less than the predicted values.
\end{abstract}

\section{INTRODUCTION}

Under favorable circumstances it is possible to relate subbottom reflectors to drilling events. When this occurs the depth to the reflector and the mean velocity of sound in the sediment above the reflector are known. In areas where the speed of sound in the sediment has been predicted by solutions from sonobuoy data, it is appropriate to compare these solutions with the drilling results. These comparisons form the basis of part of this paper which describes an attempt to assess the accuracy of the sonobuoy technique.

Another part of the paper deals with the acoustic character of the cored material. By use of regressional analysis on interval velocity solutions and, where possible, the $R_{S}-R_{1}$ technique (which will be explained), velocity gradients were estimated from sonobuoy data. Hence, it became possible to compare the sonic velocity logs with observed mean velocities from the drilling results and with the velocity gradients predicted from sonobuoy measurements.

\section{SONOBUOY TECHNIQUES}

Only minor modifications have been made to the original program of Le Pichon et al. (1968), which computes interval velocities from variable-angle reflection data on randomly dipping interfaces. These solutions are normally computed with about $5 \%$ accuracy.

Sound velocity in sediments increases with depth, and the dependence on depth must be known if sediment thickness is to be computed from an observed reflection

\footnotetext{
'Lamont-Doherty Geological Observatory of Columbia University, Contribution No. 2026.
}

time. The rate of increase can be estimated by forming regressions of interval velocities (the mean velocity within a layer) on the vertical travel time to the midpoint (in time) of each layer (Houtz et al., 1968). This results in an approximate expression for the instantaneous velocity as a function of vertical travel-time. Variance ratio tests on polynomials up to order 5 (Houtz, in press), show that there is no statistical reason for using polynomials of order greater than one. For lack of more precise information, it is therefore assumed that velocity increases linearly with vertical time, as shown in Equation (1),

$$
V=V_{o}+K T
$$

where $V_{o}$ is the initial velocity and $K$ in units of $\mathrm{km} / \mathrm{sec}^{2}$ is loosely referred to here as the velocity gradient. Expressions for the depth as a function of one-way travel time, Equation (2), and instantaneous velocity as a function of depth, Equation (3), are derived from Equation (1) by simple integration and substitution.

$$
\begin{gathered}
h=V O T=K T^{2} / 2 \\
V=\left(V o^{2}+2 K h\right)^{1 / 2}
\end{gathered}
$$

The computer techniques used to solve interval velocities from sonobuoy data do not provide reliable solutions in layers that are thinner than the water depth by about 1/12 (Houtz, in press). Accordingly, the regressional analysis predicts gross velocity gradients in the sediments from a given area, but does not resolve the gradients in the upper 300 meters or so in typical deep- 
water cases. It is clearly possible that a departure from linearity occurs in the upper part of the section where no solutions are available from such thin layers. This possibility can be tested by generating families of curves that predict the travel-time difference between a seafloor reflection and a subbottom reflection $\left(R_{S}-R_{1}\right)$ at the same range for different velocity models. For the velocity model $K$ is varied in Equation (1) from 0.5 to $4.0 \mathrm{~km} / \mathrm{sec}^{2}$ in $0.5-\mathrm{km} / \mathrm{sec}^{2}$ increments. The expressions used to generate the curves are $R_{S}-R_{1}(\mathrm{sec})$ in Equation (4) and the range, $D(\mathrm{sec})$, in Equation (5). The inputs required by the program are $K, V_{O}, T, h_{O}$ (water depth, $\mathrm{km}$ ),

$R_{s}-R_{1}=2\left\{\frac{h_{o}}{V_{v} \cos \theta_{o}}+\frac{V_{o}\left(\theta-\theta_{o}\right)}{K \sin \theta_{o}}-\left[\frac{D^{2} V_{h}{ }^{2}}{2}-h_{o}^{2}\right]\right\} 1 / 2$

$D=\frac{2}{V_{h}}\left\{h_{O} \tan \theta_{O}+\frac{V_{o}^{2}}{2 K \sin ^{2} \theta_{O}}\left[\theta-\frac{\sin 2 \theta}{2}-\theta_{O} \frac{\sin 2 \theta_{O}}{2}\right]\right\}$

and $V_{v}$ and $V_{h}$, mean vertical and surface sound channel velocities respectively. Values for $\theta_{0}$ are assigned and $\theta$ is computed from Snell's Law. Unlike previous work with $R_{S}-R_{1}$ (Ewing and Nafe, 1963), computer techniques are employed that enable one to plot points at any angle of incidence. This greatly increases accuracy when it is not possible to read $R_{S}-R_{1}$ at ranges beyond $10-12 \mathrm{~km}$, as in the present work. Observed travel-time differences are then plotted on the computed curves to find which value of $K$ best satisfies the plot of observed data.

\section{SONOBUOY RESULTS}

Sonobuoy stations relevant to Leg 29 drill holes are located on the regional map in Figure 1. Most of the sonobuoys on the Campbell Plateau were originally deployed by D. Hayes aboard Eltanin for a detailed study of the Bounty Basin (personal communication). Sites 275 and 276 were not studied due to a lack of drilling penetration. No sonobuoy data are available near Sites 278,279 , and 284 . This is also true of 277 , but the sediments at this site are similar to those elsewhere on the Campbell Plateau.

Plots of interval velocities against vertical one-way travel times from the Campbell Plateau-Bounty Basin region and from the Great Australian Bight appear in Figure 2. Computed $R_{S}-R_{1}$ curves and observed data points from sonobuoys in the Campbell-Bounty area appear in Figure 3, and one $R_{S}-R_{1}$ plot from a sonobuoy in the Tasman Sea appears in Figure 4. Not enough sonobuoys were deployed near Sites 280, 281,

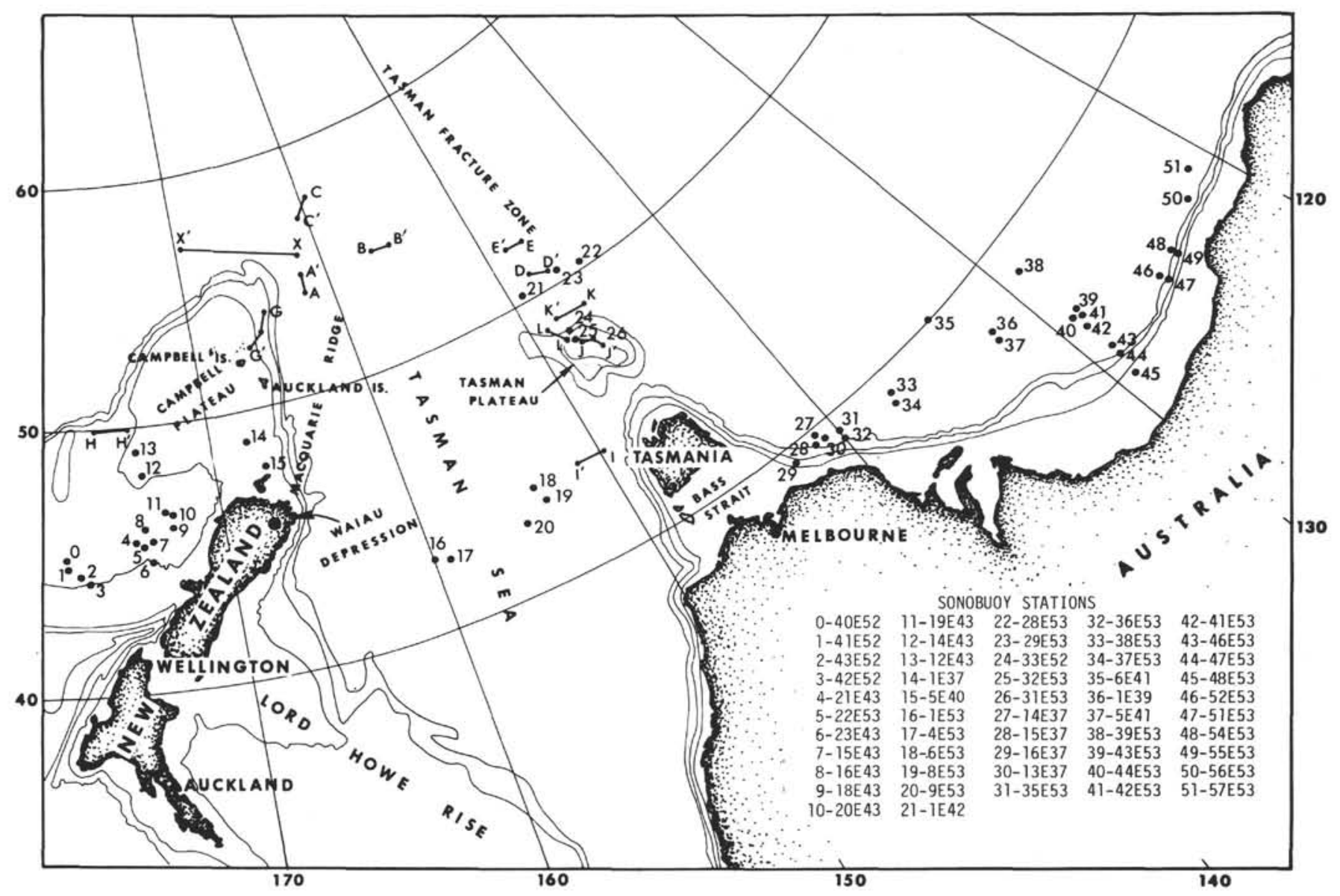

Figure 1. Locations of sonobuoys discussed in the present work. 

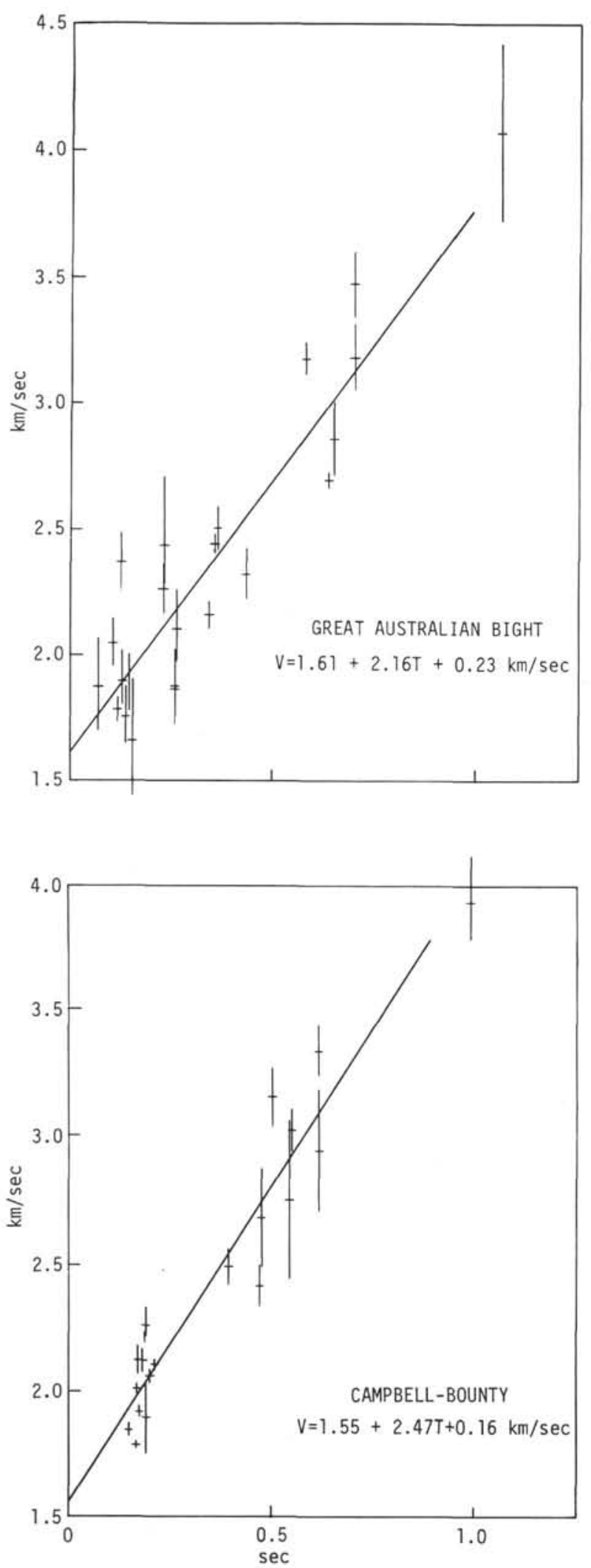

Figure 2. Regressions of interval velocities from sonobuoy solutions on one-way, vertical traveltime. Standard deviations of each solution are scaled as vertical lines. The regression coefficients are shown. and 283 to make regressional studies. However, the data from several sonobuoy solutions from nearby stations are plotted in Figure 5, so that the observed mean velocities from the drilling results can be compared with the sonobuoy data (at the appropriate depths), as shown in the figure. It is apparent that the observed values are not significantly different from the groupings of computed values.
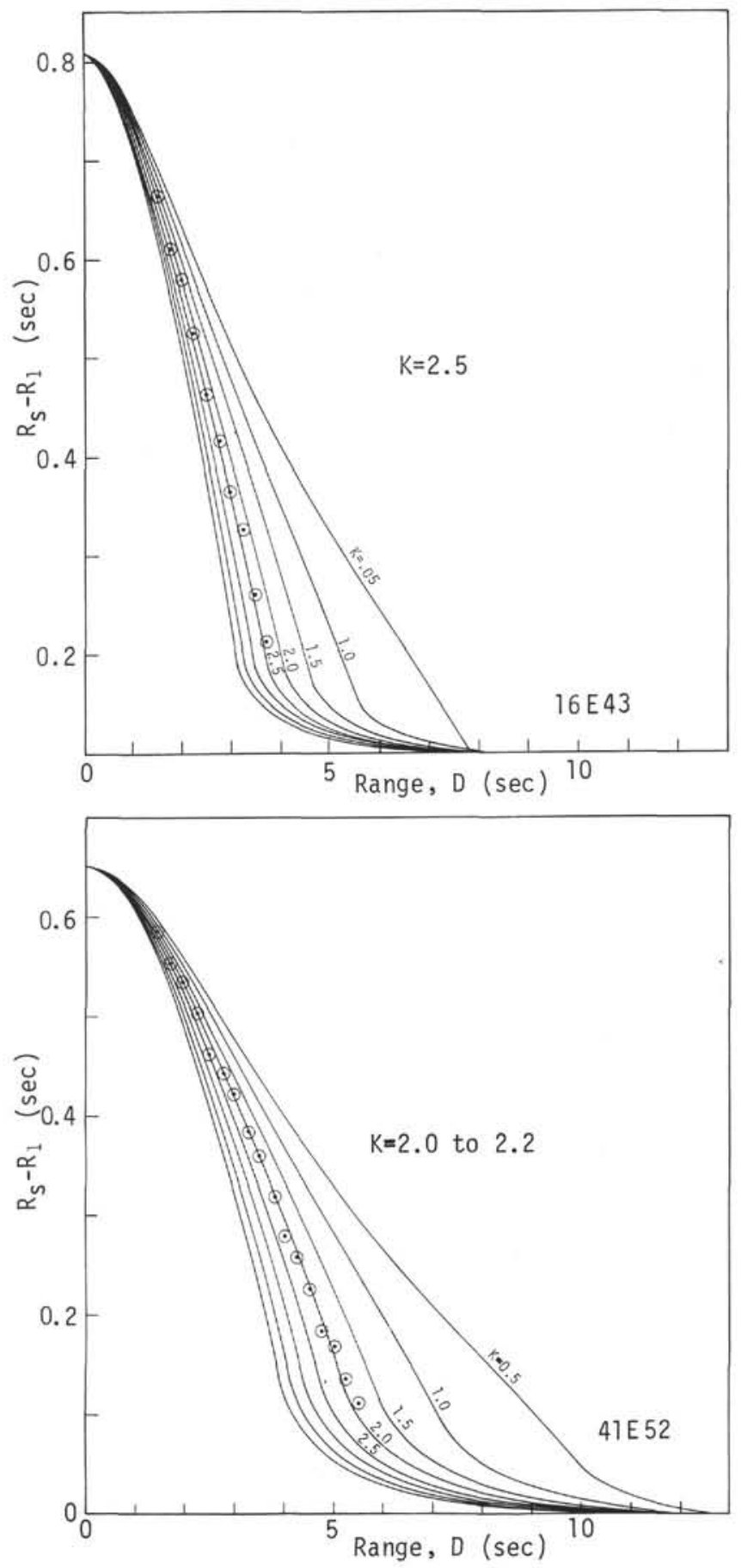

Figure 3. $R_{S}-R_{1}$ theoretical curves and plotted points from observed data in Campbell Plateau-Bounty Basin area. 


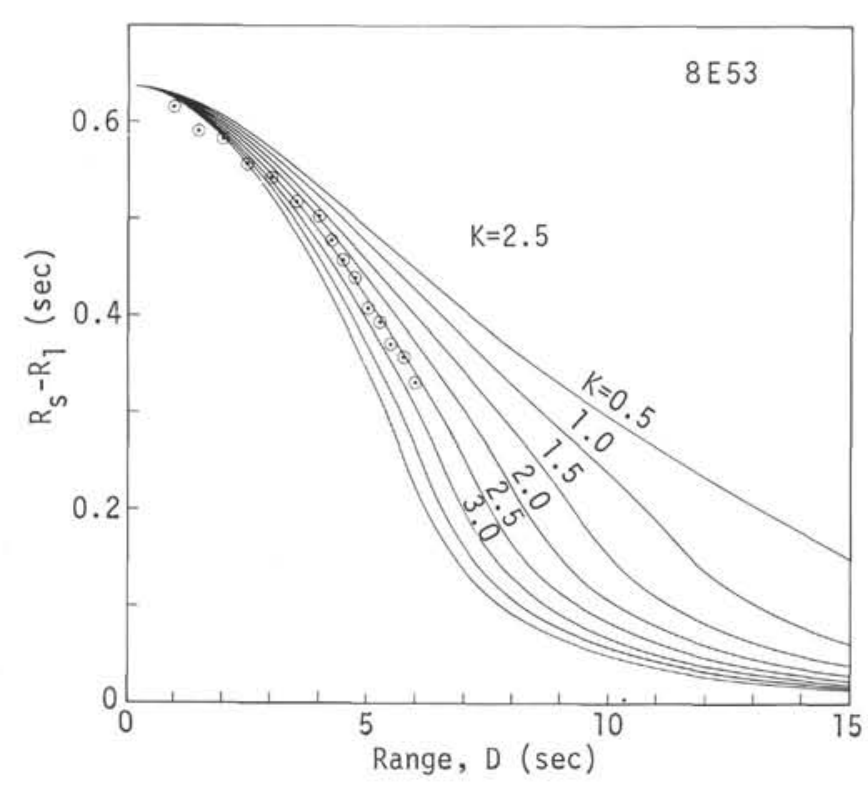

Figure 4. $R_{S}-R$, theoretical curves and plotted points from observed data in Great Australian Bight area.

The coefficients and standard error of estimate of the regression equations appear in Figure 2. The intercept value is an artifact of the least-squares fitting process, and does not necessarily bear any relation to the true velocity at the water/sediment interface, which is normally about $1.52 \mathrm{~km} / \mathrm{sec}$ in deep water. Approximate values for $K$ appear in Figures 3 and 4.

The assumption that velocity is linear in time in the upper 500 meters seems to be quite adequate for the Campbell-Bounty data because the velocity gradients obtained from the $R_{S}-R_{1}$ data are very similar to the regression coefficient shown in Figure 2. The linearity is also supported by the fact that the intercept value ( 1.55 $\mathrm{km} / \mathrm{sec}$ ) is a reasonable value for the shallow water conditions. On the other hand, a certain amount of nonlinearity is implied by the intercept of $1.61 \mathrm{~km} / \mathrm{sec}$ obtained from the Great Australian Bight data, where 1.52 $\mathrm{km} / \mathrm{sec}$ would be more likely.

\section{COMPARISON WITH DRILL RESULTS}

Table 1 lists well-determined reflection events that were identifiable during drilling, the measured depth (in $\mathrm{m})$ to these events, and the depth predicted from the sonobuoy data. The table also lists the values in the velocity equation that were used in Equation (2) to solve for thickness and, finally, the percentage difference between observed and predicted depths. No regression is available for the region near Site 283, but since $K$ is estimated as $2.5 \mathrm{~km} / \mathrm{sec}^{2}$, the velocity equation is taken to be $V=1.52+2.5 T$.

For the sake of comparison, sonobuoy solutions obtained very near Site 283 are shown in Figure 5. The rather poor agreement between the observed and computed depths at Site 283 (Table 1) seems to result from a badly determined value of $K$ (Figure 4 ) because the solutions from nearby sonobuoy stations are in close agreement with the measured drill results.
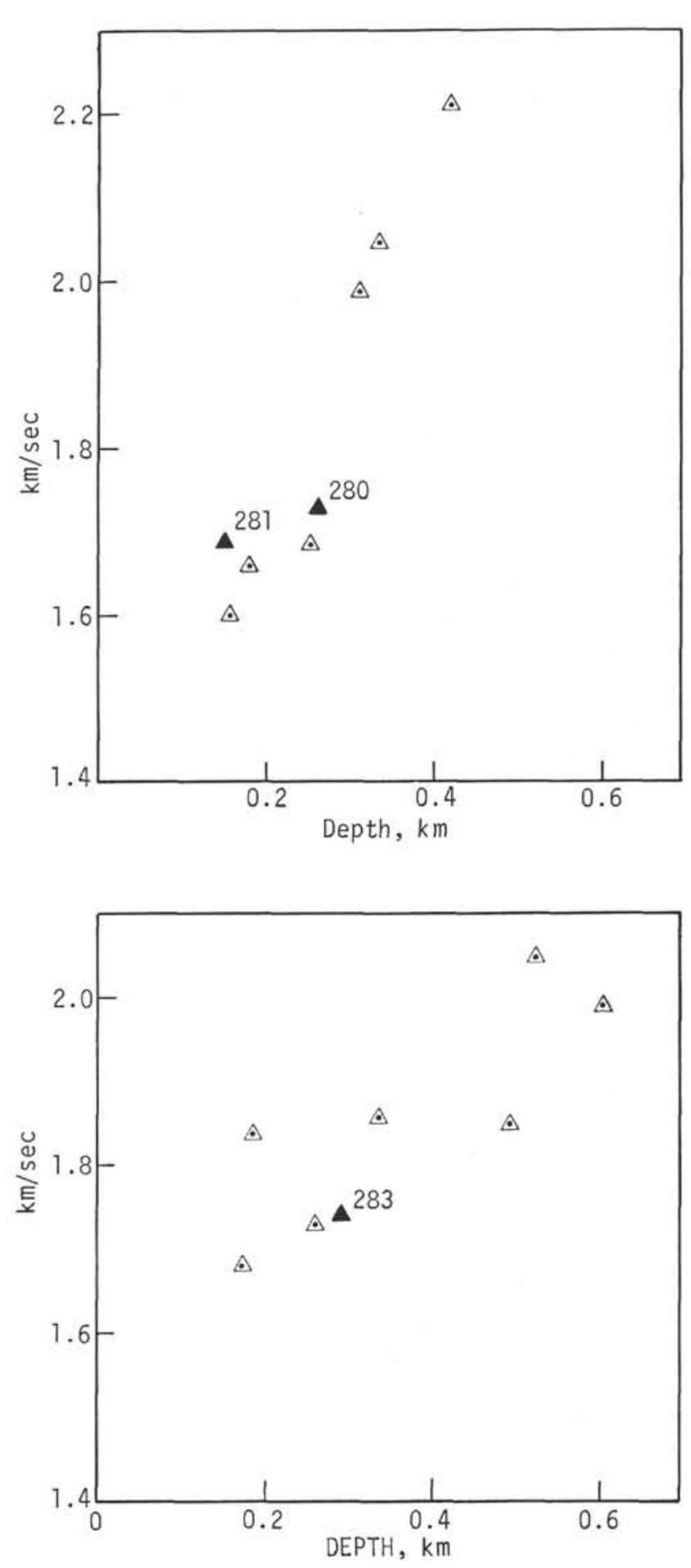

Figure 5. Velocities and depths from solutions of nearby sonobuoy stations compared to measured values at drill sites.

Wherever nearby sonobuoy results are available for comparison with drill data, such as at Sites 280,281 , and 283 , an excellent agreement is observed. Where there are no nearby sonobuoy data, but enough solutions from the same region in similar sediments, such as at Sites 
TABLE 1

Comparison of Computed and Observed Depths to Reflectors

\begin{tabular}{lcccccc}
\hline Site & $\begin{array}{c}\text { Observed } \\
\text { Reflector } \\
(\mathrm{sec})\end{array}$ & $\begin{array}{c}\text { Observed } \\
\text { Depth } \\
(\mathrm{m})\end{array}$ & $\begin{array}{c}\text { Computed } \\
\text { Depth } \\
(\mathrm{m})\end{array}$ & $\begin{array}{c}V_{o} \\
(\mathrm{~km} / \mathrm{sec})\end{array}$ & $\begin{array}{c}K \\
\left(\mathrm{~km} / \mathrm{sec}^{2}\right)\end{array}$ & $\begin{array}{c}\text { Depth } \\
\text { Difference } \\
(\%)\end{array}$ \\
\hline 277 & 0.32 & 300 & 299 & 1.55 & 2.47 & 0.3 \\
277 & 0.49 & 450 & 415 & 1.55 & 2.47 & 7.7 \\
282 & 0.35 & 295 & 315 & 1.61 & 2.16 & 6.7 \\
283 & 0.69 & 588 & 673 & 1.52 & 2.50 & 14.4 \\
Average & & & & & 7.3 \\
\hline
\end{tabular}

277 and 282 , an equally close agreement is observed. The regression method cannot be applied in areas where the sediments crop out, because the velocity/depth relation no longer applies if overburden has been removed. The Campbell-Bounty velocity function is based on shallow water solutions (depths less than $2 \mathrm{sec}$ reflection time), and the Great Australian Bight function is based on deep water solutions (greater than $2 \mathrm{sec}$ ). The functions should not be used to predict thicknesses in sediments at water depths that are not within the range of those used to make up the functions, nor should they be used unreservedly for reflection thicknesses beyond the range of the observed points (plotted as a reflection time $\div 2$ ).

\section{COMPARISON WITH SONIC MEASUREMENTS}

Sonic logs (based on the Hamilton Frame technique), with insets of the profiler sections at each site, appear in Figures 6-8. The logs were made aboard ship by occasionally averaging diverse and closely-spaced values. The variability in the sonic measurements and the lack of precision in the depths when less than full recovery was attained ( $62 \%$ recovery is the average for the leg), seems to make it unnecessary to plot the points with any more precision than that in the figures. The log of Hole 279 has been added to those holes discussed earlier. "Observed" mean velocities are computed from drilling depths and vertical travel times on the assumption of constant sound velocity in the sampled interval. These values are plotted and identified by subscripted variables that refer to the sequence of interfaces (e.g., $V_{23}$ is the mean velocity within the second and third interfaces marked with arrows on the log). The stations chosen for this study are those where the sea-floor hit was well-registered and where reflection and drilling events are fairly well correlated, ensuring reasonable accuracy for the observed mean velocities.

If it is assumed that the instantaneous velocity is linear in time, and that the water/sediment interface velocity is $1.52 \mathrm{~km} / \mathrm{sec}$, the observed mean velocity at the mid-point (in time) of the drilled layer can be used to find approximate velocity functions, i.e., solve for $K$ in Equation (1). These functions are plotted as dashed lines on the sonic logs.

The logs show quite clearly that the sonic measurements give lower values than both the observed mean velocity and the predicted instantaneous velocity, especially in sediments that were buried less than 300 meters below the sea floor. The sonic measurements tend to merge with the predicted values below 300 meters. This tendency is illustrated in Figure 9 where the mismatches between sonic and predicted values are plotted at 50-meter intervals. All the mismatches except one are positive, indicating overwhelmingly that the sonic values are less than the predicted values. A line connects the averages in the plot. The sonic data from Site 283 show the best agreement with the predicted velocities, a characteristic that may be related to the nearly complete lack of reflectors (at the frequencies employed) within these sediments.

\section{ACKNOWLEDGMENTS}

This work is based on sonobuoy and profiler data obtained by Lamont-Doherty personnel aboard USNS Eltanin. The data acquisition and reduction were therefore supported by the Office of Polar Programs. The sonobuoys were provided by the Office of Naval Research. I thank the reviewers of this paper, George Bryan and William Ludwig, for useful discussions and a critical review of the manuscript.

\section{REFERENCES}

Ewing, J. and Nafe, J., 1963. The unconsolidated sediments. In The Sea, v. 3, New York (John Wiley and Sons), p. 73-84.

Houtz, R., in press. Preliminary study of global sediment sound velocities from sonobuoy data. In Hampton, L. (Ed.), Physics of sound in marine sediments.

Houtz, R., Ewing, J., and Le Pichon, X., 1968. Velocity of deep-sea sediments from sonobuoy data: J. Geophys. Res., v. 73 , p. $2615-2641$.

Le Pichon, X., Ewing, J., and Houtz, R., 1968. Deep-sea sediment velocity determination made while reflection profiling: J. Geophys. Res., v. 73, p. 2597-2614. 

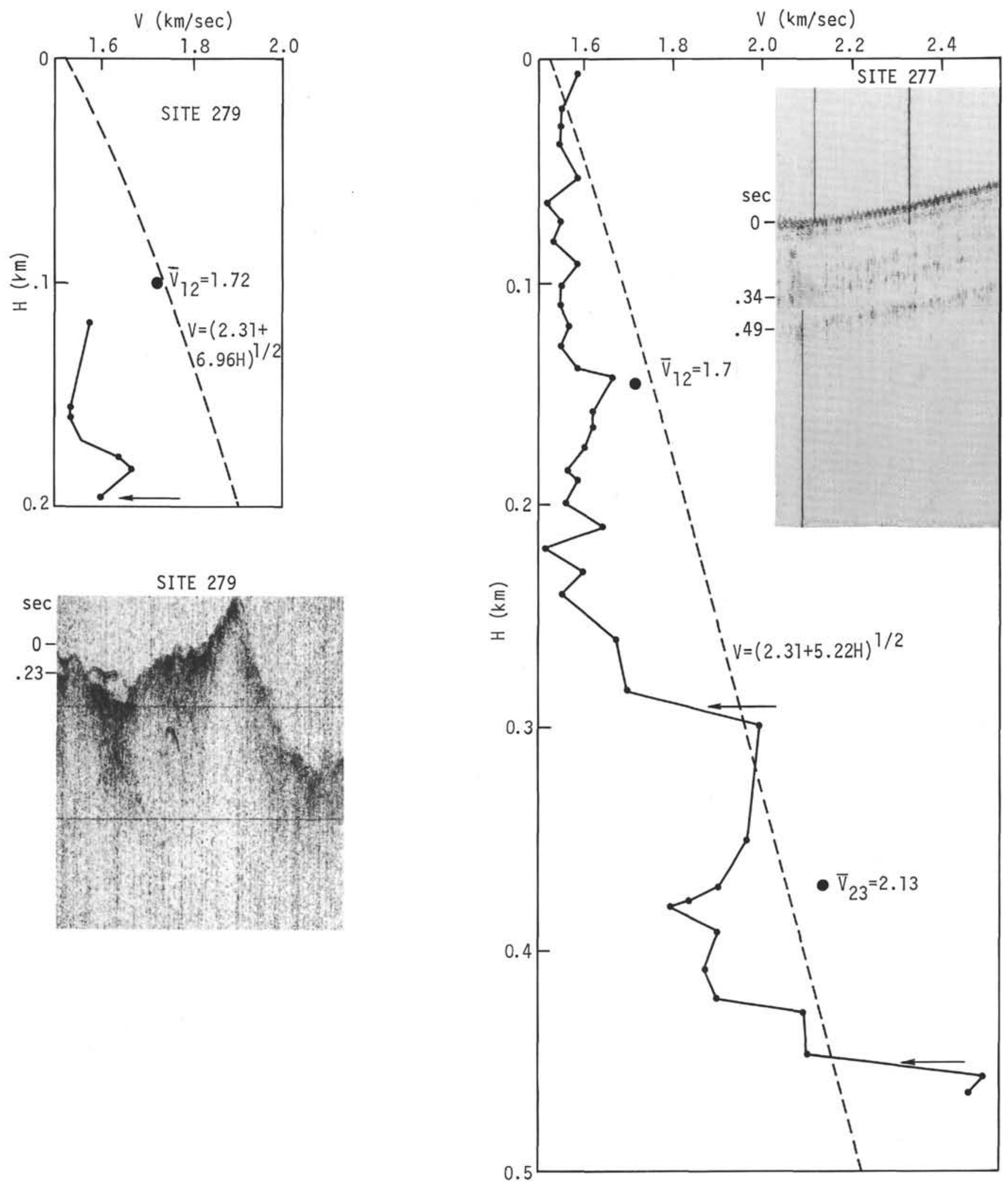

Figure 6. Predicted instantaneous velocity (dashed line) and observed mean velocities on sonic logs. 

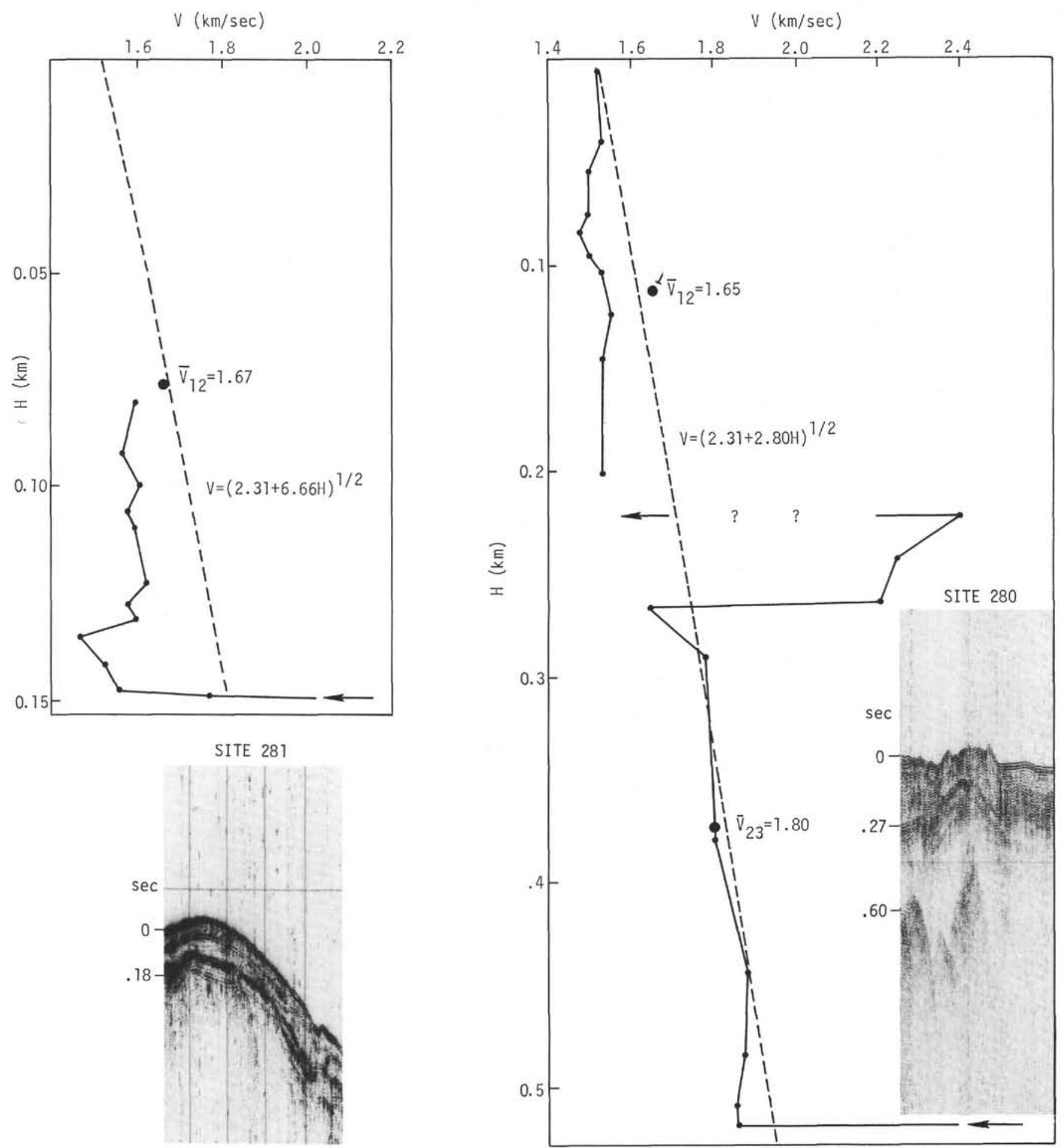

Figure 7. Predicted instantaneous velocity (dashed line) and observed mean velocities plotted on sonic logs. 

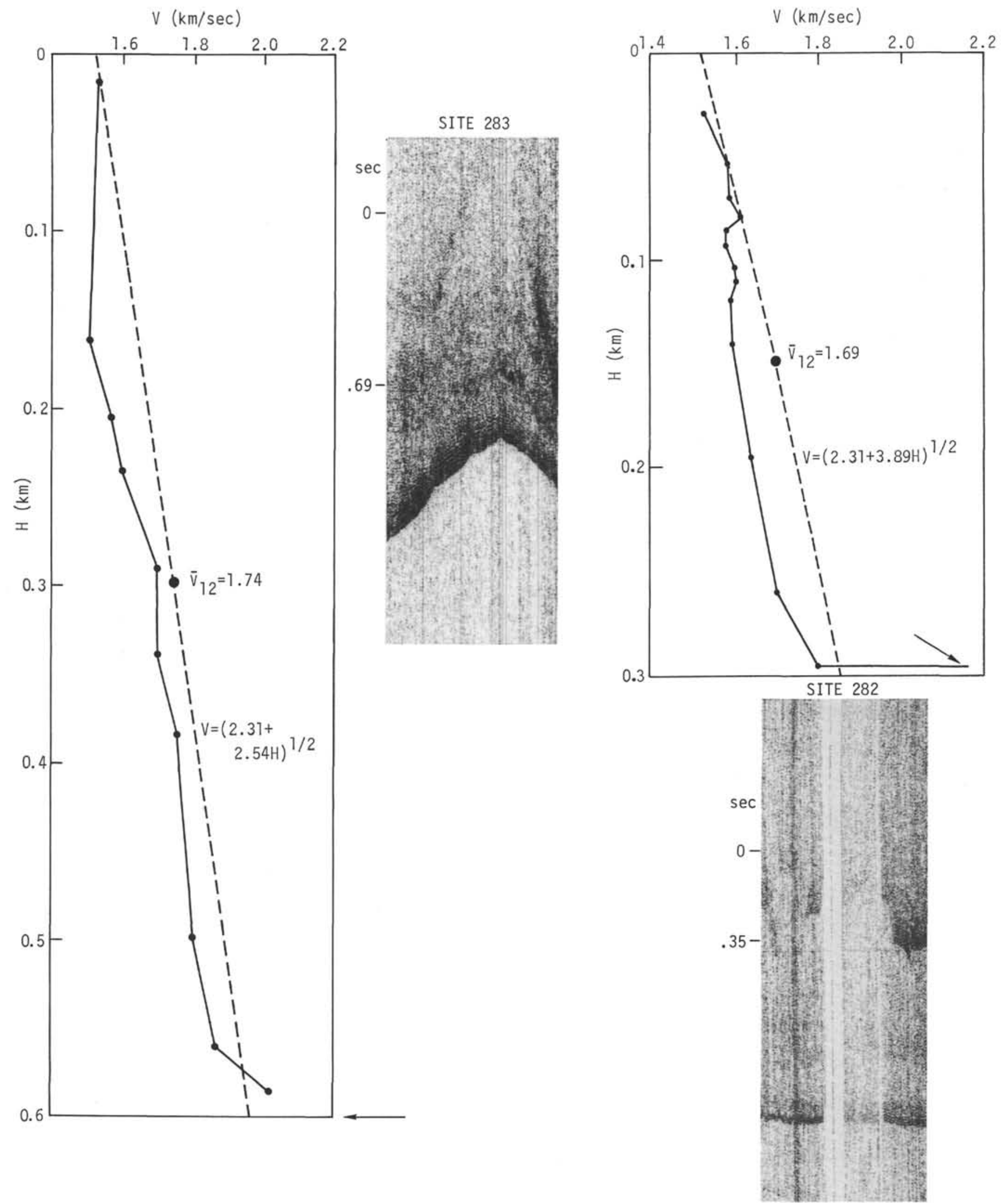

Figure 8. Predicted instantaneous velocity (dashed line) and observed mean velocities plotted on sonic logs. 


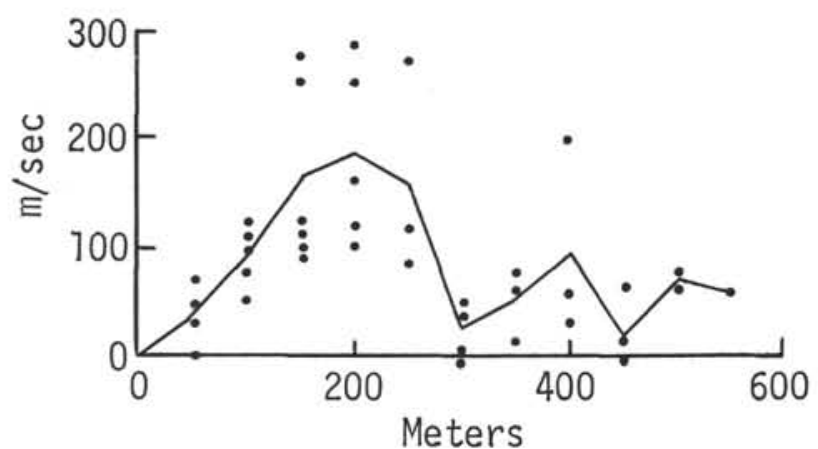

Figure 9. Mismatch of sonic velocity and predicted velocity from all Leg 29 data, plotted at 50 meter intervals. Average values connected by the straight lines. 